\title{
DO POLICY MEASURES IN FACT PROMOTE ELECTRIC MOBILITY? A STUDY ACROSS 20 COUNTRIES
}

\author{
THEO LIEVEN \& NELE RIETMANN \\ University of St. Gallen, Switzerland
}

\begin{abstract}
In a 2015 study, policy measures to promote electric mobility were examined with regard to their acceptance by consumers in 20 countries on five continents. Results of a choice-based conjoint analysis showed that people appreciate monetary incentives; however, the application of the Kano method to detect dissatisfaction with missing features revealed that charging networks are absolute must-haves. In the same 20 countries, the present article examines the actual effects of three kinds of policy measures: monetary incentives, traffic regulations in favour of electric vehicles (EVs), and investments in charging infrastructure. The outcome variable was the percentage of new registered EVs in 2016. All policy measures had positive direct effects; however, the number of existing charging stations as a moderator increased the effect of monetary measures over proportionately. The widespread uptake of EVs has been challenged by the problem that people do not accept EVs as long as the number of charging stations is insufficient, and the low number of EVs has not stimulated sufficient demand for charging stations yet. The results demonstrate how this 'chicken or the egg' dilemma will be resolved over time as soon as a sufficient number of charging stations are available. Because the effects of monetary measures and charging stations reinforce each other and the number of charging stations is accumulative, governments will be able to offer fewer and fewer monetary incentives to produce the same promoting effects.
\end{abstract}

Keywords: charging infrastructure, electric vehicles, monetary incentives, policy measures.

\section{INTRODUCTION}

Although the global share of electric vehicles (EVs) has been rising over the past years, their uptake is still relatively low in most countries around the world [1]. In order to support more widespread use of EVs, various governments have begun to offer incentives, such as financial subsidies or tax exemptions for new EV purchases, traffic regulations favouring EVs, as well as investments in the charging infrastructure [1,2]. The types and extents of such policy measures, however, differ significantly across countries, as does the share of EVs in the respective markets.

Regarding the effects of various types of policy measures, the results of Lieven's [3] 2015 study across 20 countries showed that monetary grants are the most appreciated incentives for individuals to purchase an EV. In addition, although charging networks on freeways are assumed to be absolute necessities, the free use of bus or fast lanes and city parking are not considered attractive incentives. Furthermore, the study showed that potential EV buyers prefer a charging network over a net cash grant of $\$ 6,000$. Thus, investment in charging infrastructure is probably more effective for promoting the uptake of EVs than the provision of cash grants.

Referring to this study, this article aims at further investigating these empirical findings by comparing them with actual data from 2016. Specifically, the study examines how and to what extent numerous factors, such as monetary incentives, traffic regulations, investments in infrastructure, and the number of charging stations, influence the market share of EVs. A similar study published by Sierzchula et al. [4] pointed out that financial incentives and charging infrastructure are positively correlated with EV market shares; however, there 
was no evidence of a causal effect. As the authors used data from 2012 with only very small EV market shares, in the current study, these market shares are significantly higher after four years (e.g. Norway in 2012 was 3\%, in 2016 nearly 30\% of new car registrations). The chance of finding true causal effects thus should be higher in this study. Furthermore, this study incorporates empirical data from research in the respective 20 countries assessing people's average driven mileage per day and dissatisfaction when specific policy measures are not available. Results have a clear message to policy makers regarding effective and efficient measures to promote electric mobility.

\section{METHOD AND PROCEDURE}

This study uses secondary data collected from several sources for the year 2016. The dependent variable in the subsequent analyses was the percentage of pure EVs and plug-in hybrid electric vehicles (PHEVs) registered during 2016 compared to the total number of registrations in the respective 20 countries (Australia, Belgium, Brazil, Canada, Switzerland, China, Germany, France, Hong Kong, India, Italy, Japan, Korea, the Netherlands, Norway, Russia, Taiwan, Great Britain, the United States [USA], and South Africa). The number of total vehicle sales was derived from one of the earliest motor vehicle manufacturer organizations, founded in 1919 as the Organisation Internationale des Constructeurs d'Automobiles (OICA [5]). These data distinguish between passenger cars and commercial vehicles. Only the number of passenger cars was used in this article because small trucks or pick-ups are not in a competitive position with passenger cars. This distinction is particularly important for the United States where the total number of all vehicles registered is as high as 17.9 million, but the number of passenger cars is only 6.9 million. With 158,212 EVs sold in the USA in 2016, the proportion of EVs in this study is $2.3 \%$ which is significantly higher than in other reports in which the total number of vehicles includes commercial cars. Information about EVs sold in 2016 was obtained from the Swedish consulting firm EV-Volumes [6]. These data list all vehicles by brand and model. PHEVs and EVs were considered. This might be a bias towards higher market penetration of electric mobility. However, the data include all consumers who are interested in electric propulsion. It can be expected that many of those buying PHEVs now will switch to EVs as soon as the range is long enough for the latter. A recent study in the USA with 204 participants showed that a majority of $57 \%\left(\chi^{2}=3.9, P<0.05\right)$ would prefer a pure EV over a PHEV as soon as the EV has a range of 300 miles.

Assessing monetary policy measures was more complicated in particular because even within countries the measures may not be similar in all regions. There exist many ways to provide incentives, such as direct subsidies or road tax exemptions. Some countries raise one-time taxes on the registration of vehicles which can be very high, as in Norway. All monetary measures were added for a longer period of several years. Even countries with only small one-time monetary incentives show a reasonable total monetary measure, such as Switzerland, where only a low yearly road tax must be paid instead of hundreds of Swiss francs for regular cars. Within ten years, this total adds up to 5,000 (note that the US dollar, the euro and Swiss francs are treated as being of equal value). Investments in infrastructure and traffic regulations, such as free use of fast or bus lanes, were expressed with dummy variables.

Numbers of charging stations were derived from several publications. However, sometimes whether figures mean charging locations (with one or more single charging points) or whether figures represent single plugs was indeterminate. Finally, comparing several sources 


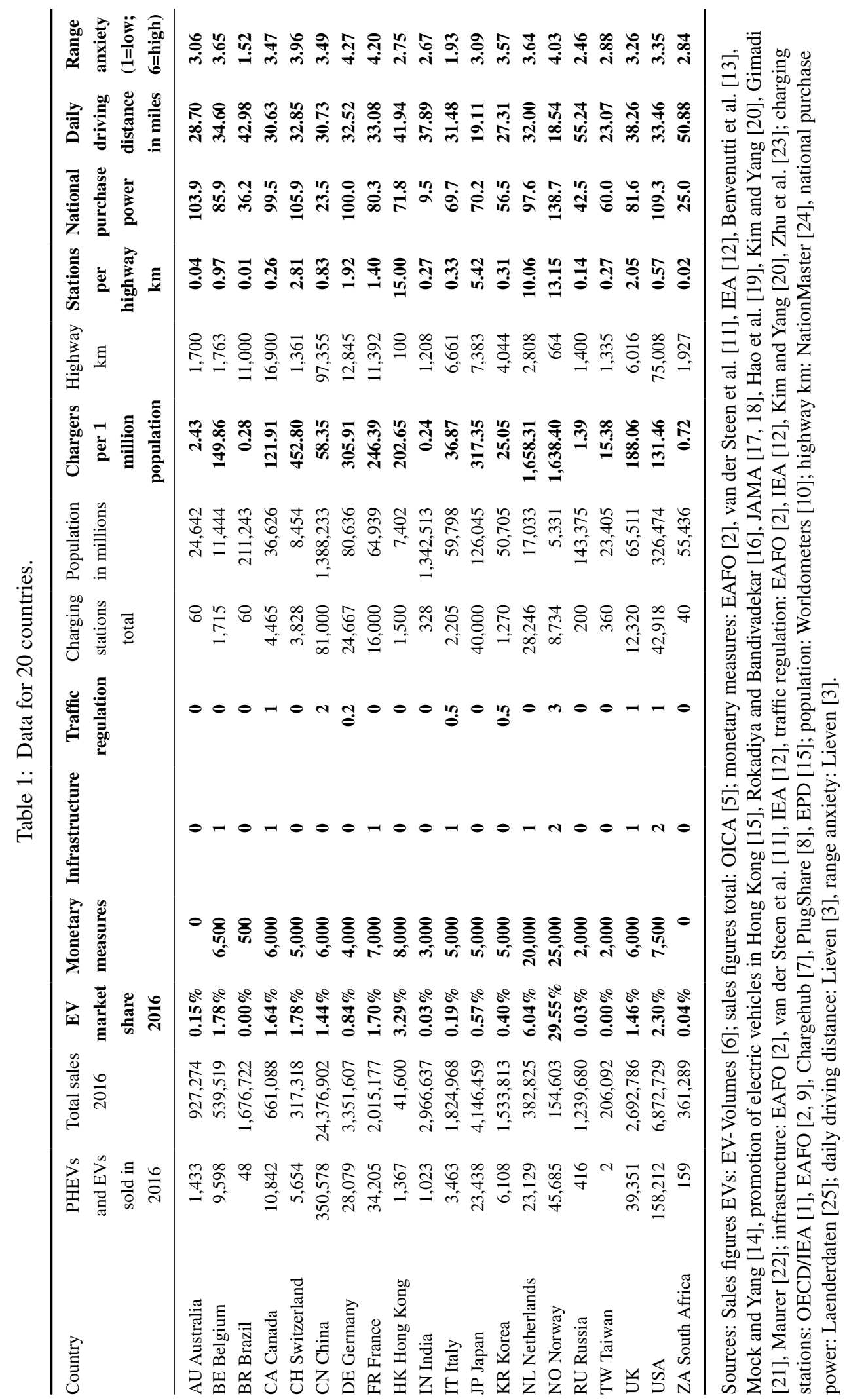


[1, 2, 7-9] led to reasonable results that represent at least the prevalence of such infrastructure. The quotient between the number of charging stations and the total population [10] can be seen as a measure of dissemination in the respective countries.

The same holds for the number of charging stations per highway kilometre [24]. In addition, the national purchasing power indices were added to the analyses [25]. From a worldwide survey in the respective 20 countries, the daily driving distances were known, as well as drivers' range anxiety [3]. The complete set of data is depicted in Table 1.

The data were analysed in a simultaneous equation model with partial least squares regression (PLS [26]). The respective model is depicted in Fig. 1. The bold variables in Table 1 were included in the model and data from a worldwide study with 8,147 participants in the above-mentioned countries [3]. These were the results of a conjoint analysis with respondents' utilities of monetary measures, traffic regulations such as free use of bus lanes or city parking and charging infrastructure. Furthermore, dissatisfaction indices derived from the Kano model [27] were included in the PLS regression. These indices measured the degree to which respondents were disappointed if these measures were not available. In Fig. 1, the interaction term of monetary measures and number of charging stations is included. In the initial model, this was not the case.

\section{RESULTS}

We do not report significances in the PLS model because the limited number of cases (20) makes the $t$-values quite low. However, the significance of the bivariate correlations can be seen in Table 2.

We report Cohen's effect size $f^{2}$ [28] which is independent of sample size [29] and is an evaluation of the increase in the coefficient of determination when the respective variable is included. This $R^{2}$ value is a measure of the portion of the dependent variable's variance that could be explained. In the initial model without interaction terms, all three utilities positively influenced the respective measures $\left(\beta_{\text {Monetary }}=0.29, f^{2}=0.11 ; \beta_{\text {Traffic Regulations }}=0.15, f^{2}=0.02\right.$; $\left.\beta_{\text {Infrastructure }}=0.22, f^{2}=0.09\right)$. The effect of utilities on measures means that the higher the consumers' utility of policy measures, the more such policy measures exist. This measure reveals governments' willingness to follow their populations' needs and requests. This result is supported by a decline in dissatisfaction with stronger measures $\left(\beta_{\text {Monetary }}=-0.56, f^{2}=0.45\right.$; $\beta_{\text {Traffic Regulations }}=-0.36, f^{2}=0.15 ; \beta_{\text {Infrastructure }}=-0.09, f^{2}=0.01$ ).

As can be expected, national purchase power positively supports policy measures $\left(\beta_{\text {Monetary }}\right.$ $=0.73, f^{2}=0.78 ; \beta_{\text {Traffic Regulations }}=0.29, f^{2}=0.09 ; \beta_{\text {Infrastructure }}=0.63, f^{2}=0.72$ ). According to the $R^{2}$ values, $42 \%$ of the variance in the monetary measures can be explained, $12 \%$ of the variation in the traffic regulations by $12 \%$, and $45 \%$ of the variation in the infrastructure investments.

Two of the three measures positively affect the EV market share $\left(\beta_{\text {Monetary }}=0.73, f^{2}=0.37\right.$; $\left.\beta_{\text {Traffic Regulations }}=0.19, f^{2}=0.09\right)$. The number of charging stations seems to mediate the direct effect of infrastructure measures $\left(\beta_{\text {Chargers }}=0.16, f^{2}=0.05\right)$. This mediation indicates that infrastructure measures increase the number of charging stations, which, in turn, increases the EV market share. A look at the control variables reveals that the more miles people drive the lower their range anxiety $\left(\beta_{\text {Distance }}=-0.43, f^{2}=0.23\right)$. This range anxiety, however, increases the number of installed charging stations $\left(\beta_{\text {Range Anxiety }}=0.27, f^{2}=0.09\right)$.

Eighty-nine per cent of the variation in the EV market share was explained in this model $\left(R^{2}=0.89\right)$. A further examination included the interaction term of monetary measures and the number of installed charging stations as can be seen in Fig. 1. This interaction suppresses 


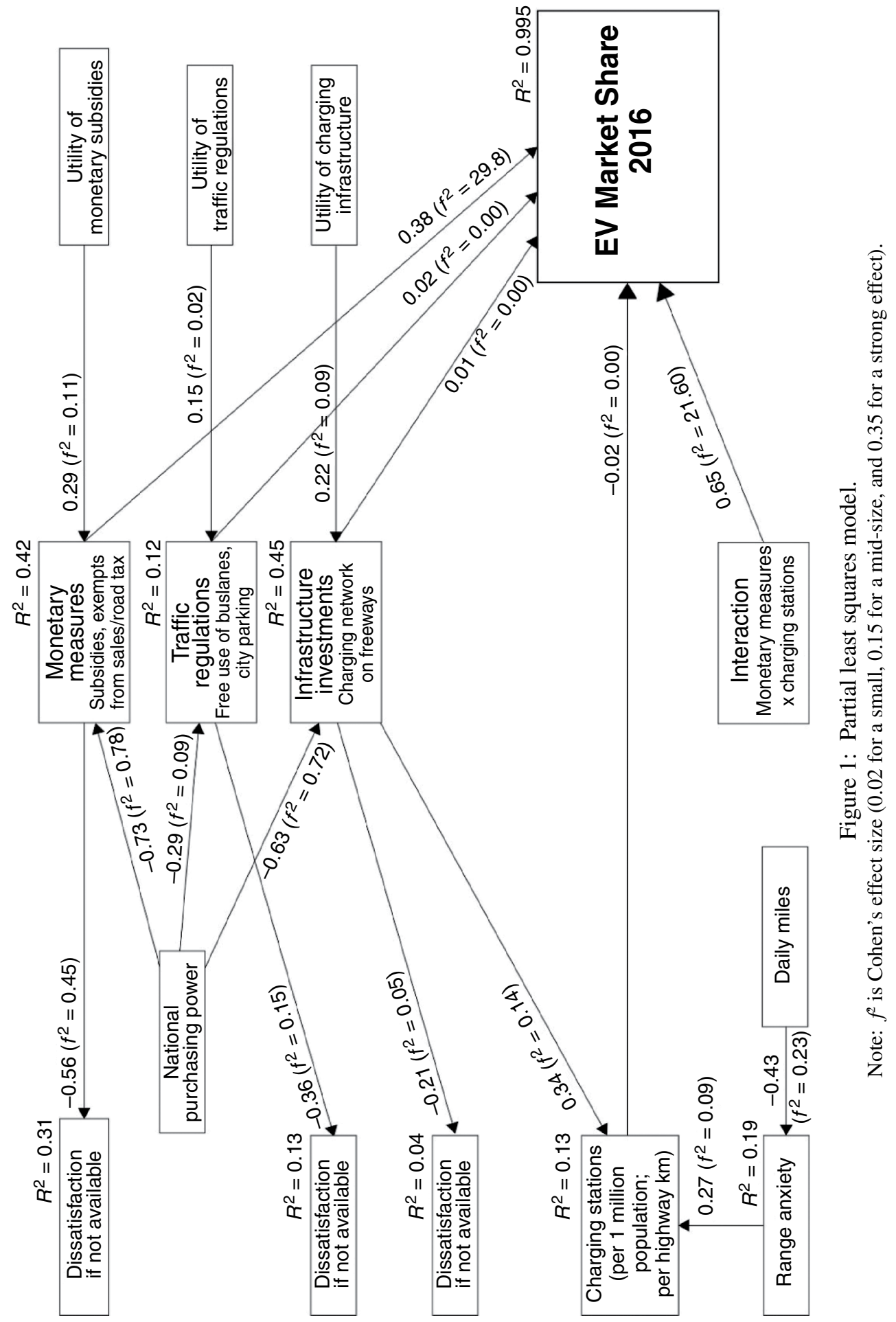




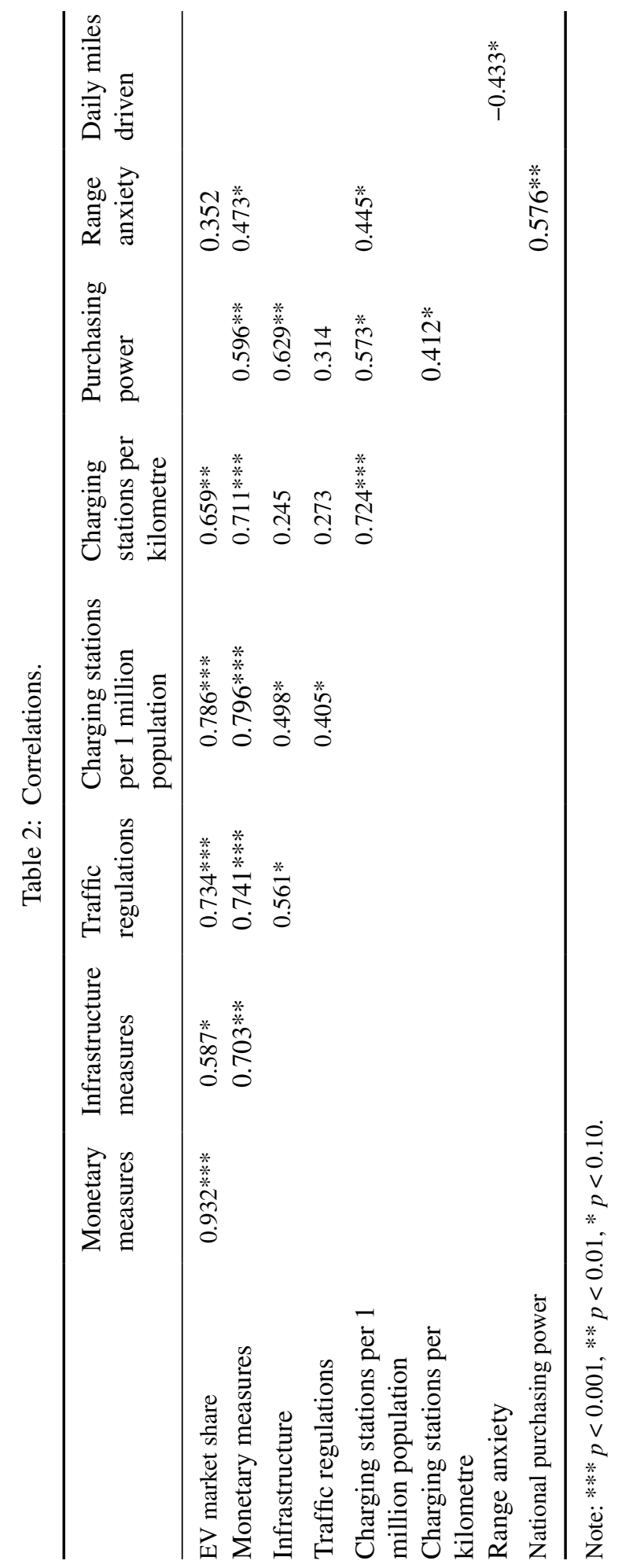




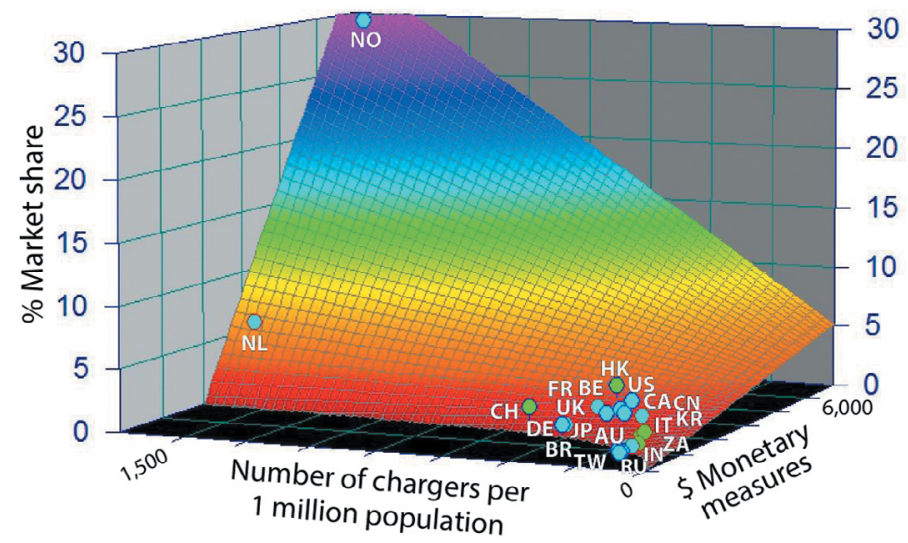

Figure 2: Percentage of EVs in 20 countries (interaction included).

the effect of traffic regulations and the direct effect of the number of charging stations. The direct effect of monetary measures is reduced $\left(\beta_{\text {Monetary }}=0.38, f^{2}=0.30\right)$. The interaction, however, positively affects the percentage of $\operatorname{EVs}\left(\beta_{\text {Interaction }}=0.66, f^{2}=0.22\right)$. This modification results in an explained variance in the outcome variable (EV percentage) of nearly $100 \%$.

How important the interaction term is can also be seen from Fig. 2. In the three-dimensional space, the EV percentages nearly fit the function exactly, including the interaction term $\left(R^{2}=0.993\right)$ :

$$
\mathrm{EV} \%=\beta_{0}+\beta_{1} \cdot M+\beta_{2} \cdot N+\beta_{3} \cdot M \cdot N
$$

where $M$ is the monetary measures and $N$ is the number of charging stations, $\beta_{0}=1.23$; $\beta_{1}=2.77, p<0.001 ; \beta_{2}=-0.45$, n.s.; $\beta_{3}=1.90, p<0.001$. In the interaction model (Fig. 2 ), the mere effect of monetary measures is much smaller, as is the effect of charging stations (which is slightly negative but is not statistically significant). An important increase in the EV percentage is explained by the interaction term.

\section{DISCUSSION, LIMITATIONS AND CONCLUSION}

This study with real data is in line with the empirical results. Lieven [3] pointed out that monetary policy measures are appreciated by consumers; however, charging infrastructure is a must-have. Analyses of the actual percentage of EVs registered in 2016 show that the interaction term contributes significantly. Thus, the finding from consumer research that governments should not concentrate on monetary measures only but should also include infrastructure projects was supported in this study.

This finding is even more important because investments in infrastructure are more efficient. Allowing EVs free use of bus lanes or city parking is effective but is not efficient because of the congestion effects with an increasing number of EVs. Because monetary measures are paid individually, no increasing efficiency will occur over time. Installing charging stations, however, becomes increasingly efficient because they not only are used by today's EV drivers but also will be used by future EV drivers. Thus, the effects of investments in charging infrastructure sum over time while monetary measures are paid once with a one-time effect and do not sum. Briefly, a monetary incentive attracts only one EV buyer 
while the installation of a charger attracts many potential EV buyers. Based on the example in Lieven [3], with a US government budget of \$3 billion, such as in the 2009 Cash for Clunkers programme, it would be wiser to install 6,000 fast chargers along interstate highways and pay an incentive of $\$ 3,000-700,000 \mathrm{EV}$ buyers than to give approximately 333,000 EV buyers a grant of $\$ 9,000$.

The fact that policy measures are stronger in countries where consumers' perceived utility of such measures is higher and dissatisfaction about missing measures is lower emphasizes the plausibility of the model and the data. The strong effects that can be seen in Figs 1 and 2 point towards a possible limitation of this study concerning problems caused by outliers. Such outliers could be the Netherlands and - above all - Norway. Outliers can have serious distortion effects on regression results. Especially, outliers can represent the only reason a significant causal effect is falsely identified. However, Norway is not an outlier in the classical sense as a randomly outside situated data point. It is more the political will of Norway's government than a mere coincidence that the percentage of $\mathrm{EV}$ registrations was so high in 2016. Norway offers numerous tax incentives, rebates, subsidies and loosening of traffic restrictions to EV owners [30,31]. Almost one-third of all new registered cars in Norway were EVs. From this outstanding percentage, it can safely be concluded that this result is causally induced by the magnitude of Norwegian policy measures. Thus far, this study could enhance Sierzchula et al.'s [4] warning about the uncritical acceptance of a causal relationship between financial incentives, charging infrastructure and EV market share. According to our data, these causal effects exist. The same holds in some way for the Netherlands. The question remains, how the model would perform without these two exceptional examples. To examine this point, Norway and the Netherlands were removed from the sample, and the regression from eqn (1) was repeated including the interaction term. The regression itself was statistically significant $\left(R^{2}=0.84, F(3,14)=24.46, p<0.001\right)$ with statistically significant positive coefficients $\left(\beta_{0}=1.69 ; \beta_{1}=3.92, p<0.001 ; \beta_{2}=1.68, p<0.01 ; \beta_{3}=5.46, p<0.01\right.$; Fig. 3). This means that even if one assumes Norway and the Netherlands are outliers, the main finding of this study holds with significant and positive causal effects of monetary measures and infrastructure investments on EV market share.

This study enhances the existing literature as real data in 20 countries from 2016 supported preferences previously stated in these countries in 2014. Results are promising and could

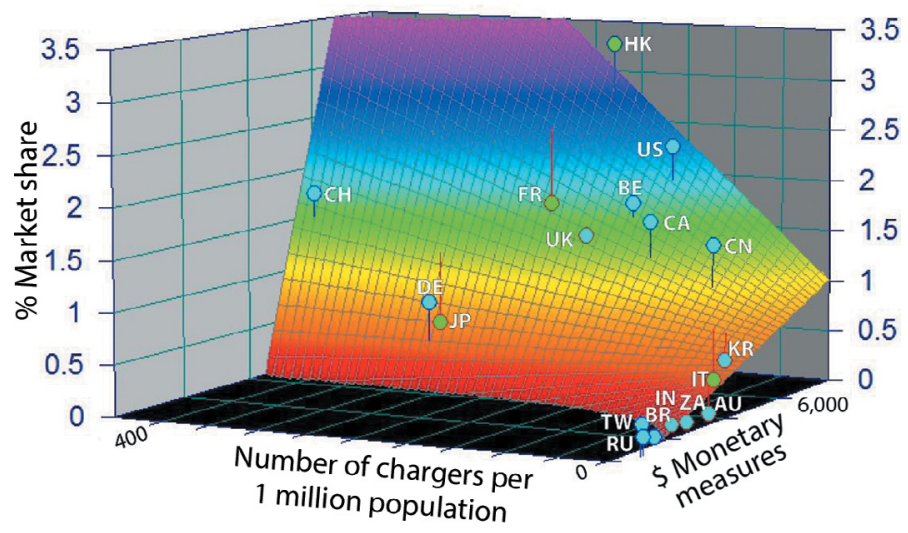

Figure 3: Percentage of EVs excluding Norway and the Netherlands (interaction included). 
encourage governments to promote the acceptance of electric mobility with a balanced policy in favour of direct financial subsidies combined with intense support for charging infrastructure. This policy does not necessarily have to be cost intensive as regulations could encourage building owners to implement a sufficient number of charging stations, particularly in metropolitan areas. The direct and interaction effects will increase the percentage of EVs in these countries even more.

\section{REFERENCES}

[1] OECD/IEA, Global EV outlook 2016: beyond one million electric cars, Int. Energy Agency 2016, available at https://www.iea.org/publications/freepublications/publication/ global-ev-outlook-2016.html, 2016 (accessed 18 April 2017).

[2] EAFO, Incentives \& Legislation, available at http://www.eafo.eu/incentives-legislation, n.d. (accessed 6 April 2017).

[3] Lieven, T., Policy measures to promote electric mobility - a global perspective. Transportation Research Part A: Policy and Practice, 82, pp. 78-93, 2015. DOI: 10.1016/j. tra.2015.09.008.

[4] Sierzchula, W., Bakker, S., Maat, K. \& Van Wee, B., The influence of financial incentives and other socio-economic factors on electric vehicle adoption. Energy Policy, 68, pp. 183-194, 2014. DOI: 10.1016/j.enpol.2014.01.043.

[5] OICA, Organisation Internationale des Constructeurs d'Automobiles, available at http://www.oica.net/category/about-us/, n.d. (accessed 20 June 2017).

[6] EV-volumes, available at http://www.ev-volumes.com/, n.d. (accessed 20 June 2017).

[7] Chargehub, Charging Stations, available at https://chargehub.com/en/charging-stationsmap.html, n.d (accessed 24 July 2017).

[8] PlugShare, EV Charging Station Map, available at https://www.plugshare.com/\#, n.d. (accessed 26 April 2017).

[9] EAFO, European Alternative Fuels Observatory, available at http://www.eafo.eu/ electric-vehicle-charging-infrastructure, n.d (accessed 25 July 2017).

[10] Worldometers, World Population by Country, available at http://www.worldometers. info/world-population/, n.d (accessed 2 May 2017).

[11] van der Steen, M., van Schelven, R.M., Kotter, R., van Twist, M.J.W. \& van Deventer, P., EV policy compared: an international comparison of governments' policy strategy towards e-mobility. E-Mobility in Europe. Trends and Good Practice, eds. W.L. Filho \& R. Kotter, Springer: Cham, pp. 27-53, 2015.

[12] IEA, International Energy Agency, Annual Reports 2005-2016, available at: http:// www.ieahev.org/news/annual-reports/, 2016 (accessed 27 July 2017).

[13] Benvenutti, L.M.M., Ribeiro, A.B., Forcellini, F.A. \& Maldonado, M.U., The effectiveness of tax incentive policies in the diffusion of electric and hybrid cars in Brazil. 41st Congr. Latinoam. Din. Sist. São Paulo, 2016.

[14] Mock, P. \& Yang, Z., Driving electrification - a global comparison of fiscal incentive policy for electric vehicles. Int. Counc. Clean Transp 2014., available at http://www. theicct.org/sites/default/files/publications/ICCT_EV-fiscal-incentives_20140506.pdf, 2014 (accessed 27 July 2017).

[15] Environmental Protection Department, Promotion of Electric Vehicles in Hong Kong, available at http://www.epd.gov.hk/epd/english/environmentinhk/air/prob_solutions/ promotion_ev.html, n.d. (accessed 3 April 2017). 
[16] Rokadiya, S. \& Bandivadekar, A., Hybrid and electric vehicles in India - current scenario and market incentives. Int. Counc. Clean Transp. (ICCT), Work Pap 2016, available at http://www.theicct.org/sites/default/files/publications/India-hybrid-andEV-incentives_working-paper_ICCT_27122016.pdf, 2016 (accessed 27 July 2017).

[17] JAMA, Japanese government incentives for the purchase of environmentally friendly vehicles. Japan Automob. Manuf. Assoc. 2010, available at http://www.jama.org/ japanese-government-incentives-for-the-purchase-of-environmentally-friendlyvehicles/, 2010 (accessed 27 July 2017).

[18] JAMA, The motor industry of Japan. Japan Automob. Manuf. Assoc. 2010, available at http://jama-english.jp/publications/MIJ2010.pdf, 2010 (accessed 27 July 2017).

[19] Hao, H., Ou, X., Du, J., Wang, H. \& Ouyang, M., China's electric vehicle subsidy scheme: rationale and impacts. Energy Policy, 73, pp. 722-732, 2014. DOI: 10.1016/j. enpol.2014.05.022.

[20] Kim, S. \& Yang, Z., Promoting electric vehicles in Korea. Int. Counc. Clean Transp. 2016, available at http://www.theicct.org/blogs/staff/promoting-electric-vehicles-inkorea, 2016 (accessed 27 July 2017).

[21] Gimadi, V., Subsidizing purchases of electric cars would make perfect sense. Anal. Cent. Gov. Russ. Fed. 2016, available at http://ac.gov.ru/en/commentary/09599.html, 2016 (accessed 27 July 2017).

[22] Maurer, J., Taiwan setzt bei Elektromobilität Prioritäten. Ger. Trade Invest 2014, available at http://www.gtai.de/GTAI/Navigation/DE/Trade/Maerkte/suche,t=taiwan-setzt-beielektromobilitaet-prioritaeten,did=1081172.html, 2014 (accessed 27 July 2017).

[23] Zhu, G., Hein, C.T. \& Ding, Q., Case study - China's regulatory impact on electric mobility development and the effects on power generation and the distribution grid. ed. J. Liebl, Grid Integr. Electr. Mobil. 1st Int. ATZ Conf., Springer: Wiesbaden, pp. 13-29, 2017.

[24] NationMaster, Motorway Length by Country, available at http://www.nationmaster. com/country-info/stats/Transport/Road/Motorway-length, n.d (accessed 2 May 2017).

[25] Laenderdaten, Purchasing Power Indices by Country, available at https://www. laenderdaten.info/lebenshaltungskosten.php, n.d (accessed 2 May 2017).

[26] Ringle, C.M., Wende, S. \& Will, S., SmartPLS 2.0 (M3) Beta, www.smartpls.de, 2005 (accessed 14 January 2017).

[27] Kano, N., Seraku, N., Takahashi, F. \& Tsuji, S., Attractive quality and must-be quality. Journal of the Japanese Society for Quality Control, 14, pp. 39-48, 1984. NAID: 10017961938.

[28] Cohen, J., Statistical Power Analysis for the Behavioral Sciences, 2nd ed., Lawrence Erlbaum Associates: Hillsdale, NJ, 1988.

[29] Selya, A.S., Rose, J.S., Dierker, L.C., Hedeker, D. \& Mermelstein, R.J., A practical guide to calculating Cohen' s f2, a measure of local effect size, from PROC MIXED. Frontiers in Psychology, 3, pp. 1-6, 2012. DOI: 10.3389/fpsyg.2012.00111.

[30] Lindquist, K. \& Wendt, M., Electric vehicle policies, fleet, and infrastructure: synthesis. Transp. Synth. Reports Washingt. State Dep. Transp., pp. 1-35, available at http://www. wsdot.wa.gov/NR/rdonlyres/5559AE0E-8AB5-4E6B-8F8B-DEAA7ECE715D/0/ SynthesisEVPoliciesFleetandInfrastructureFINALRev112911.pdf, 2011 (accessed 25 July 2017).

[31] Trip, J.J., Lima, J. \& Bakker, S., Electric mobility policies in the North Sea Region countries. Eur. Union - Rep. Writ. within Framew Act 33 Interreg IVB Proj. E-Mobility NSR, File $N r$ 35-2-6-11, pp. 1-64, available at http://e-mobility-nsr.eu/fileadmin/user_upload/NEWS/Electric_mobility_policies_in_the_North_Sea_Region_countries/3.3_-E-mobility_policies_in_the_NSR_countries.pdf, 2012 (accessed 2 May 2017). 